\title{
The effect of pay-for-performance program on infection events and mortality rate in diabetic patients: a nationwide population- based cohort study
}

Yi-Fang Wu ${ }^{1 \dagger}$, Mei-Yen Chen ${ }^{2,3+}$, Tien-Hsing Chen ${ }^{4,5,6}$, Po-Chang Wang ${ }^{7}$, Yun-Shing Peng ${ }^{8}$ and Ming-Shyan Lin ${ }^{2,7,9^{*}}$

\begin{abstract}
Background: Diabetes mellitus is a known risk factor for infection. Pay for Performance (P4P) program is designed to enhance the comprehensive patient care. The aim of this study is to evaluate the effect of the P4P program on infection incidence in type 2 diabetic patients.

Methods: This is a retrospective longitudinal cohort study using data from the National Health Insurance Research Database in Taiwan. Diabetic patients between 1 January 2002 and 31 December 2013 were included. Primary outcomes analyzed were patient emergency room (ER) infection events and deaths.

Results: After propensity score matching, there were 337,184 patients in both the P4P and non-P4P cohort. The results showed that patients' completing one-year P4P program was associated with a decreased risk of any ER infection event (27.2\% vs. 29\%; subdistribution hazard ratio [HR] 0.87, 95\% confidence interval [CI] 0.86-0.88). While the number needed to treat was 58 for the non-P4P group, it dropped to 28 in the P4P group. The risk of infection-related death was significantly lower in the P4P group than in the non-P4P group (4.1\% vs. 7.6\%; HR 0.46, 95\% $\mathrm{Cl}$ 0.45-0.47). The effect of P4P on ER infection incidence and infection-related death was more apparent in the subgroups of patients who were female, had diabetes duration $\geq 5$ years, chronic kidney disease, higher Charlson's Comorbidity Index scores and infection-related hospitalization in the previous 3 years.
\end{abstract}

Conclusions: The P4P program might reduce risk of ER infection events and infection-related deaths in type 2 diabetic patients.

Keywords: Pay-for-performance, Infection, Sepsis, Diabetes, Mortality

\section{Background}

Diabetes mellitus (DM) affected 463 million adults worldwide [1]. Its prevalence has increased over the past 10 years, reaching up to $9 \%$ of world population in 2019 , with

\footnotetext{
* Correspondence: mingshyan@gmail.com

${ }^{+}$Yi-Fang Wu and Mei-Yen Chen contributed equally to this work.

2Department of Nursing, Chang Gung University of Science and Technology, Chiayi, Taiwan

${ }^{7}$ Department of Cardiology, Chang Gung Memorial Hospital, Chiayi, Taiwan
} Full list of author information is available at the end of the article nearly $20 \%$ of patients being over 65 years old [1]. Diabetes is not only a metabolic disease, but it is also associated with multiple comorbidities, including chronic kidney disease (CKD), retinopathy, cardiovascular disease, stroke, and infections [2]. Over $10 \%$ of the global health expenditure is spent on diabetes treatment [3], with the total healthcare cost per diabetic patient being approximately 2.8 times higher than that of a non-diabetic patient [4].

Infection is the second leading cause of death in type 2 diabetes mellitus patients (T2DM), accounting for $10 \%$ of

(c) The Author(s). 2021 Open Access This article is licensed under a Creative Commons Attribution 4.0 International License, which permits use, sharing, adaptation, distribution and reproduction in any medium or format, as long as you give appropriate credit to the original author(s) and the source, provide a link to the Creative Commons licence, and indicate if changes were made. The images or other third party material in this article are included in the article's Creative Commons licence, unless indicated otherwise in a credit line to the material. If material is not included in the article's Creative Commons licence and your intended use is not permitted by statutory regulation or exceeds the permitted use, you will need to obtain permission directly from the copyright holder. To view a copy of this licence, visit http://creativecommons.org/licenses/by/4.0/ The Creative Commons Public Domain Dedication waiver (http://creativecommons.org/publicdomain/zero/1.0/) applies to the data made available in this article, unless otherwise stated in a credit line to the data. 
the annual emergency room (ER) visits and $12 \%$ of hospitalizations respectively $[5,6]$. Diabetic patients are more likely than non-diabetic patients to develop sepsis, recurrent infections, hospitalization, shock, and mortality [7-9]. Therefore, there is a need for more medical interventions and more comprehensive diabetes care in order to diminish the risk of infection among T2DM patients [8].

Pay for Performance (P4P) program has been implemented in order to increase health care efficiency in many countries, including the United States, United Kingdom, Germany, and Taiwan [10]. Comparing with other diseases such as coronary heart disease and stroke, $\mathrm{P} 4 \mathrm{P}$ program in DM had showed the highest rate of medical care quality improvement $[11,12]$. The P4P program was initiated in Taiwan for enhancing diabetes care since November 2001 [13], more than one quarter of diabetic patients are enrolled in the program annually [14]. After patients' enrollment in the P4P program, a team of care providers, consisting of physicians, nurses, nutritionists, and other healthcare professionals work together to provide serial examinations, health education, and follow-up services. Previous studies have showed that the P4P program, aimed at tackling diabetes, effectively increased clinical guideline adherence, quality of care, physician continuity, and decreased inpatient care utilization [13, 15-17].

Considering the improvement in diabetes care, we hypothesized that the P4P program will reduce infectionrelated complications and mortality rate in T2DM patients. Because previous research has smaller patient sample size and is limited on subgroup analysis of mortality and ER infections $[18,19]$, we conducted the present populationbased study to address the relationship between infection associated outcomes and the diabetes P4P program.

\section{Methods}

\section{Data source}

This is a retrospective longitudinal cohort study using data from the Taiwan National Health Insurance Research Database (NHIRD). The National Health Institute (NHI) Program, launched in March 1995, provides 99\% of medical coverage for the 23 million residents in Taiwan. The NHIRD claims information from the NHI program and is updated biannually and validated by the Taiwan's Bureau of National Health Insurance (BNHI). The NHIRD contains data of outpatient and inpatient services, including diagnosis, medication, interventions, operations, hospitalizations, and emergent visits. Diagnosis is registered using the International Classification of Diseases, Ninth Revision, Clinical Modification (ICD-9$\mathrm{CM}$ ) codes. All patient information in the NHIRD is deidentified to protect privacy. For reference further information regarding NHI and NHIRD has been described in previous publications $[20,21]$. The institutional review board of the Chang Gung Memorial Hospital approved this study (IRB No.:202000134B1).

\section{Pay for performance program in Taiwan}

The diabetes P4P program was established in 2001 by the BNHI ([13], https://www.nhi.gov.tw/Content_List. aspx $? \mathrm{n}=95611 \mathrm{DD} 9 \mathrm{DDCAF} 987 \&$ topn $=5$ FE8C9FEAE863 B46). Patients who participated in the P4P program went through diet and health management education, annual laboratory tests (including $\mathrm{HbAlc}$, fasting sugar, creatinine, alanine aminotransferase (ALT), total cholesterol, low-density lipoprotein (LDL), triglyceride (TG), highdensity lipoprotein (HDL), and urinalysis), and serial physical examinations (ex. ophthalmic evaluation and fundoscopic exam) in order to enhance their comprehensive diabetes care $[15,22]$. Diabetic patients were enrolled in the P4P program in Taiwan with payment coding as $\mathrm{P} 1407 \mathrm{C}$ and received follow-up services every three months (P1408C). Patients who completed enrollment and more than two follow-ups in the first year went through an annual examination and were labeled as completing the first year P4P program (P1409C).

We used payment coding (P1409C) as completing the first year P4P program. Institutions (health care providers) that fulfilled the annual $\mathrm{P} 4 \mathrm{P}$ requirements were qualified to receive financial support from the NHI. The health care providers are granted 650 NT dollars per qualified patient per physician, $400 \mathrm{NT}$ dollars per new enrolled patient, 200 NT dollars per follow-up per patient and $800 \mathrm{NT}$ dollars per qualified patient to the institution [21].

\section{Inclusion criteria and study design}

We identified patients who were diagnosed as diabetes with use of any oral hypoglycemic agents between 1 January 2002 and 31 December 2013 using data obtained from the NHIRD. Patients who were diagnosed as type 1 DM (T1DM), less than 20 years-old, and had missing demographic information were excluded from the analysis. Patients who participated in the P4P program but did not qualify for the first-year program were excluded. A total of 369,194 adult T2DM patients in the P4P group were eligible for analysis. The date of completing the first-year program was set as the index date of the P4P group. Adult T2DM patients who did not participate in the P4P program were selected as the control group $(n=951,989)$. To avoid the immortal time bias, the index date of the control group was assigned as the date on which the T2DM patients in the P4P group finished the first-year program [23]. The patients in the $\mathrm{P} 4 \mathrm{P}$ group were propensity score matched to those in the non-P4P group with a $1: 1$ ratio, yielding 337,184 patients in either group (Fig. 1). 


\section{Covariates}

Covariates in this study were patents' age at the index date, sex, urbanization level, monthly income, diabetes duration, health care utilization in the previous year (number of outpatient visit related to diabetes, outpatient visit, emergency room visit and hospitalization), twelve comorbidities, Charlson's Comorbidity Index (CCI) score, history of cardiovascular events (heart failure, ischemic stroke, hemorrhage stroke), history of infection events (infection-related hospitalization in the previous year and number of infection-related hospitalization in the previous 3 years), intake of seven types of diabetes medication and other medications (Table 1). Comorbidities were identified as having at least 2 outpatient diagnoses or an inpatient diagnosis in the previous year. The ICD-9-CM diagnostic codes of the comorbidities are listed in Supplemental Table 1. Patients' medical history was identified by looking at any inpatient diagnosis made before the index date. All the information regarding medication intake in the year before the index date were extracted from the claim data of outpatient visits or the refill requests for chronic illness medication in the pharmacy using the Anatomical Therapeutic Chemical codes or the Taiwan NHI reimbursement code.

\section{Outcomes}

The primary outcomes were patients' first visit to the emergency room (ER) due to infection after the index date (any ER infection event) and infection-related death. Based on a previous study the infection sites included bacteremia, cardiovascular, central nervous system, respiratory, gastrointestinal (GI), genitourinary (GU), musculoskeletal and device-related infection (Supplemental Table 1) [24]. The infection-related death was determined by examining the cause of death in the main diagnosis in the discharge records for inpatient hospital deaths, the primary diagnosis of the last ER visit, or hospitalization within 7 days of death for out-of-hospital deaths [24]. Secondary outcomes were the number of all-cause ER visits, infection-related ER visits, all-cause hospitalization, infection-related hospitalization, and allcause mortality during the follow up. In Taiwan, the most common reason for withdrawal from the NHI program was death, the other less common reasons include emigration or being missing more than 6 months. Therefore, a withdrawal from the NHI program was considered death in this study [25]. All patients were followed from the index date (the date of completing the first year $\mathrm{P} 4 \mathrm{P}$ program for the $\mathrm{P} 4 \mathrm{P}$ group) to the date of event,

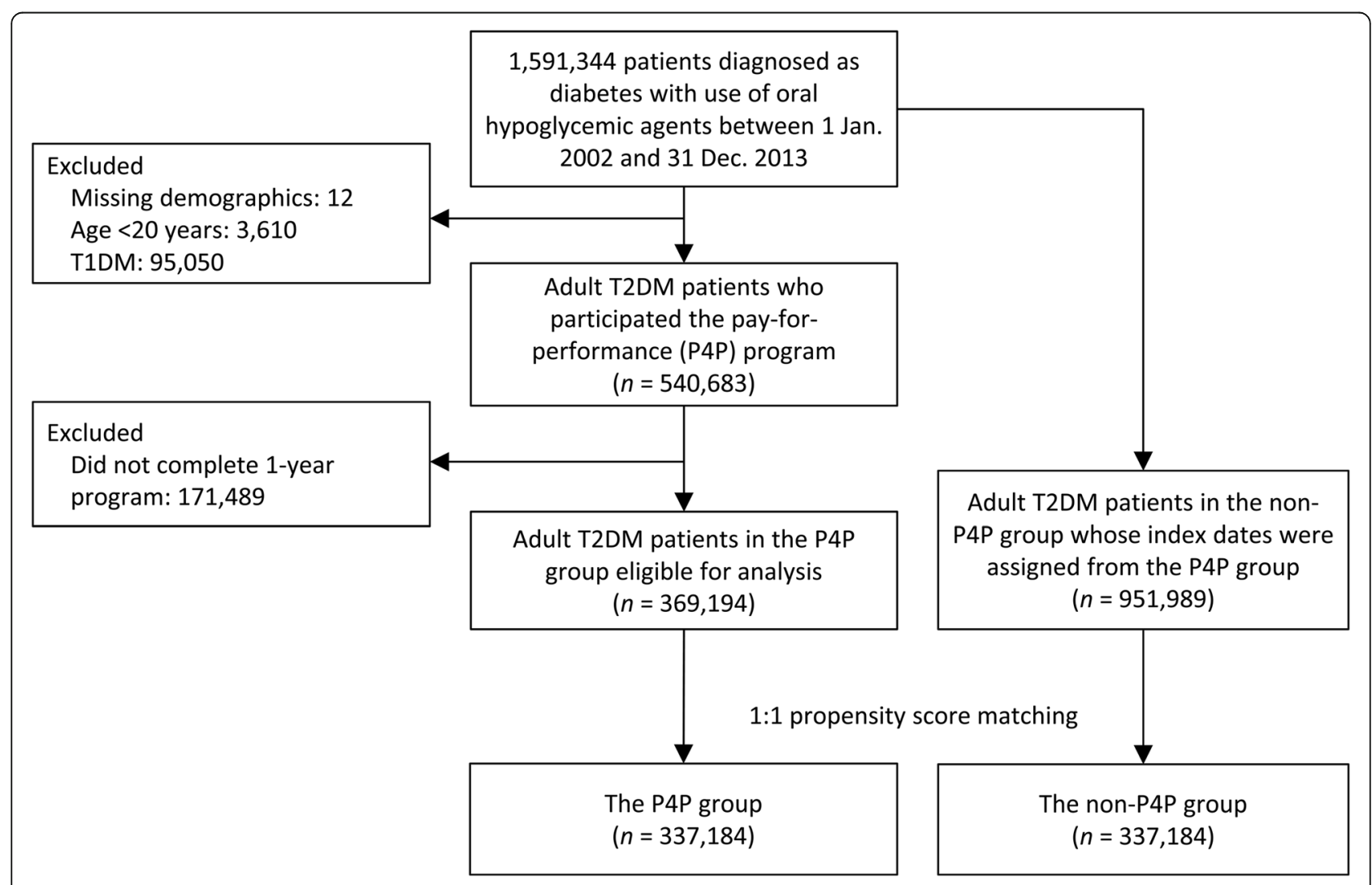

Fig. 1 Patient selection. T1DM, type 1 diabetes mellitus; T2DM, type 2 diabetes mellitus; P4P, pay for performance 
Table 1 Baseline characteristics of patients according to completing 1-year pay-for-performance program or not

\begin{tabular}{|c|c|c|c|c|c|c|}
\hline \multirow[t]{2}{*}{ Variable } & \multicolumn{3}{|c|}{ Data before matching } & \multicolumn{3}{|c|}{ Data after matching } \\
\hline & $\begin{array}{l}\text { P4P }(n=369, \\
194)\end{array}$ & $\begin{array}{l}\text { Non-P4P }(n=951 \text {, } \\
\text { 989) }\end{array}$ & STD & $\begin{array}{l}\text { P4P }(n=337, \\
184)\end{array}$ & $\begin{array}{l}\text { Non- P4P }(n=337 \text {, } \\
\text { 184) }\end{array}$ & STD \\
\hline Age (years; mean $\pm S D$ ) & $60.9 \pm 11.8$ & $63.0 \pm 13.5$ & $-\overline{0.17}$ & $61.0 \pm 11.8$ & $61.1 \pm 12.9$ & $\begin{array}{l}< \\
0.01\end{array}$ \\
\hline Male & $182,531(49.4)$ & $471,689(49.5)$ & $\begin{array}{l}< \\
0.01\end{array}$ & $166,940(49.5)$ & $166,928(49.5)$ & $\begin{array}{l}< \\
0.01\end{array}$ \\
\hline \multicolumn{7}{|l|}{ Urban level } \\
\hline Low & $41,918(11.4)$ & $113,792(12.0)$ & -0.02 & $37,964(11.3)$ & $37,115(11.0)$ & 0.01 \\
\hline Moderate & $121,999(33.0)$ & $295,819(31.1)$ & 0.04 & $110,255(32.7)$ & $109,306(32.4)$ & 0.01 \\
\hline High & $113,856(30.8)$ & $279,267(29.3)$ & 0.03 & $103,690(30.8)$ & $103,591(30.7)$ & $\begin{array}{l}< \\
0.01\end{array}$ \\
\hline Very High & $91,421(24.8)$ & $263,111(27.6)$ & -0.07 & $85,275(25.3)$ & $87,172(25.9)$ & -0.01 \\
\hline \multicolumn{7}{|l|}{ Monthly income, NTD } \\
\hline $0-17,880$ & $84,853(23.0)$ & $260,210(27.3)$ & -0.10 & $78,630(23.3)$ & $78,457(23.3)$ & $\begin{array}{l}< \\
0.01\end{array}$ \\
\hline $17,881-22,800$ & $151,438(41.0)$ & $374,004(39.3)$ & 0.04 & $137,209(40.7)$ & $136,259(40.4)$ & 0.01 \\
\hline$>22,800$ & $132,903(36.0)$ & $317,775(33.4)$ & 0.06 & $121,345(36.0)$ & $122,468(36.3)$ & -0.01 \\
\hline Diabetes duration (years) & $5.8 \pm 4.2$ & $4.4 \pm 3.8$ & 0.36 & $5.5 \pm 4.1$ & $5.4 \pm 4.1$ & 0.03 \\
\hline \multicolumn{7}{|l|}{ Health care utilization in the previous year } \\
\hline No. of outpatient visit of diabetes & $14.4 \pm 7.5$ & $9.6 \pm 8.1$ & 0.62 & $13.8 \pm 6.9$ & $13.9 \pm 8.7$ & $\overline{-}-02$ \\
\hline No. of outpatient visit & $34.1 \pm 21.2$ & $31.9 \pm 22.8$ & 0.10 & $33.5 \pm 20.9$ & $33.5 \pm 21.7$ & $\begin{array}{l}< \\
0.01\end{array}$ \\
\hline No. of emergent room visit & $0.37 \pm 1.09$ & $0.60 \pm 1.81$ & $\begin{array}{l}- \\
0.16\end{array}$ & $0.37 \pm 1.11$ & $0.37 \pm 0.99$ & 0.01 \\
\hline No. of hospitalization & $0.21 \pm 0.67$ & $0.50 \pm 1.25$ & $-\overline{0.29}$ & $0.22 \pm 0.68$ & $0.22 \pm 0.63$ & 0.01 \\
\hline \multicolumn{7}{|l|}{ Comorbidity } \\
\hline COPD & $15,402(4.2)$ & $64,115(6.7)$ & $-\overline{0.11}$ & $14,296(4.2)$ & $13,929(4.1)$ & 0.01 \\
\hline Hypertension & $216,200(58.6)$ & $555,549(58.4)$ & $\begin{array}{l}< \\
0.01\end{array}$ & $197,115(58.5)$ & $199,661(59.2)$ & -0.02 \\
\hline PAOD & $9503(2.6)$ & $22,965(2.4)$ & 0.01 & $8440(2.5)$ & $8237(2.4)$ & $\begin{array}{l}< \\
0.01\end{array}$ \\
\hline Ischemic heart disease & $48,383(13.1)$ & $151,326(15.9)$ & -0.08 & $44,215(13.1)$ & $44,268(13.1)$ & $\begin{array}{l}< \\
0.01\end{array}$ \\
\hline VTE & $573(0.16)$ & $3600(0.38)$ & -0.04 & $531(0.2)$ & $553(0.2)$ & $\begin{array}{l}< \\
0.01\end{array}$ \\
\hline Dyslipidemia & $198,296(53.7)$ & $331,620(34.8)$ & 0.39 & $174,589(51.8)$ & $177,147(52.5)$ & -0.02 \\
\hline Auto-immune disease & $1470(0.40)$ & $4537(0.48)$ & -0.01 & $1332(0.4)$ & $1229(0.4)$ & $\begin{array}{l}< \\
0.01\end{array}$ \\
\hline Liver disease & $55,012(14.9)$ & $131,221(13.8)$ & 0.03 & $50,036(14.8)$ & $50,954(15.1)$ & -0.01 \\
\hline Liver cirrhosis & $4738(1.3)$ & $22,978(2.4)$ & -0.08 & $4483(1.3)$ & $4338(1.3)$ & $\begin{array}{l}< \\
0.01\end{array}$ \\
\hline Chronic kidney disease & $62,472(16.9)$ & $118,749(12.5)$ & 0.13 & $52,110(15.5)$ & $49,095(14.6)$ & 0.03 \\
\hline Dialysis & $987(0.27)$ & $20,406(2.1)$ & -0.17 & $982(0.3)$ & $864(0.3)$ & 0.01 \\
\hline Malignancy & $17,569(4.8)$ & $63,038(6.6)$ & -0.08 & $16,312(4.8)$ & $16,194(4.8)$ & $\begin{array}{l}< \\
0.01\end{array}$ \\
\hline Charlson's Comorbidity Index score & $2.1 \pm 1.4$ & $2.1 \pm 1.9$ & 0.03 & $2.1 \pm 1.4$ & $2.1 \pm 1.6$ & $\begin{array}{l}< \\
0.01\end{array}$ \\
\hline
\end{tabular}

History of event 
Table 1 Baseline characteristics of patients according to completing 1-year pay-for-performance program or not (Continued)

\begin{tabular}{|c|c|c|c|c|c|c|}
\hline \multirow[t]{2}{*}{ Variable } & \multicolumn{3}{|c|}{ Data before matching } & \multicolumn{3}{|c|}{ Data after matching } \\
\hline & $\begin{array}{l}\text { P4P }(n=369, \\
194)\end{array}$ & $\begin{array}{l}\text { Non-P4P }(n=951 \text {, } \\
\text { 989) }\end{array}$ & STD & $\begin{array}{l}\text { P4P }(n=337, \\
184)\end{array}$ & $\begin{array}{l}\text { Non- P4P }(n=337 \text {, } \\
\text { 184) }\end{array}$ & STD \\
\hline Heart failure & $8910(2.4)$ & $56,558(5.9)$ & -0.18 & $8391(2.5)$ & $8131(2.4)$ & $\begin{array}{l}< \\
0.01\end{array}$ \\
\hline Ischemic stroke & $23,773(6.4)$ & $112,059(11.8)$ & -0.19 & $22,222(6.6)$ & $21,623(6.4)$ & 0.01 \\
\hline Hemorrhage stroke & $2916(0.79)$ & $17,700(1.9)$ & -0.09 & $2782(0.8)$ & $2593(0.8)$ & 0.01 \\
\hline \multicolumn{7}{|l|}{ History of infection event } \\
\hline Infection-related hospitalization in the previous year & $16,698(4.5)$ & $103,888(10.9)$ & -0.24 & $15,856(4.7)$ & $15,119(4.5)$ & 0.01 \\
\hline $\begin{array}{l}\text { No. of infection-related hospitalization in the previ- } \\
\text { ous } 3 \text { years }\end{array}$ & $0.19 \pm 0.62$ & $0.42 \pm 1.33$ & -0.22 & $0.19 \pm 0.63$ & $0.18 \pm 0.63$ & 0.02 \\
\hline \multicolumn{7}{|l|}{ Medication } \\
\hline NSAID & $71,133(19.3)$ & $192,047(20.2)$ & -0.02 & $65,091(19.3)$ & $65,577(19.4)$ & $\begin{array}{l}< \\
0.01\end{array}$ \\
\hline COX-II inhibitors & $19,254(5.2)$ & $56,323(5.9)$ & -0.03 & $17,609(5.2)$ & $17,709(5.3)$ & $\begin{array}{l}< \\
0.01\end{array}$ \\
\hline Aspirin & $91,631(24.8)$ & $209,685(22.0)$ & 0.07 & $81,838(24.3)$ & $81,656(24.2)$ & $\begin{array}{l}< \\
0.01\end{array}$ \\
\hline Clopidogrel & $5910(1.6)$ & $27,195(2.9)$ & -0.09 & $5467(1.6)$ & $5309(1.6)$ & $\begin{array}{l}< \\
0.01\end{array}$ \\
\hline Statin & $149,217(40.4)$ & $231,072(24.3)$ & 0.35 & $128,993(38.3)$ & $128,449(38.1)$ & $\begin{array}{l}< \\
0.01\end{array}$ \\
\hline Anticoagulant & $2365(0.64)$ & $11,360(1.2)$ & -0.06 & $2200(0.7)$ & $2170(0.6)$ & $\begin{array}{l}< \\
0.01\end{array}$ \\
\hline Steroid & $9995(2.7)$ & $38,984(4.1)$ & -0.08 & $9267(2.7)$ & $9044(2.7)$ & $\begin{array}{l}< \\
0.01\end{array}$ \\
\hline \multicolumn{7}{|l|}{ Antidiabetic medication } \\
\hline Metformin & $262,652(71.1)$ & $501,270(52.7)$ & 0.39 & $238,004(70.6)$ & $247,512(73.4)$ & -0.06 \\
\hline DDP4 inhibitors & $39,894(10.8)$ & $43,154(4.5)$ & 0.24 & $31,211(9.3)$ & $28,355(8.4)$ & 0.03 \\
\hline Sulfonylureas (SU) & $228,801(62.0)$ & $476,608(50.1)$ & 0.24 & $208,035(61.7)$ & $215,388(63.9)$ & -0.05 \\
\hline Thiazolidinedione & $59,132(16.0)$ & $66,562(7.0)$ & 0.29 & $49,003(14.5)$ & $46,951(13.9)$ & 0.02 \\
\hline Non-SU insulin secretagogues & $26,464(7.2)$ & $51,341(5.4)$ & 0.07 & $23,150(6.9)$ & $23,284(6.9)$ & $\begin{array}{l}< \\
0.01\end{array}$ \\
\hline Alpha glucosidase inhibitors & $50,046(13.6)$ & $72,429(7.6)$ & 0.19 & $42,604(12.6)$ & $42,000(12.5)$ & 0.01 \\
\hline Insulin & $46,794(12.7)$ & $47,945(5.0)$ & 0.27 & $34,747(10.3)$ & 28,952 (8.6) & 0.06 \\
\hline Follow-up (years; mean \pm SD) & $4.5 \pm 3.0$ & $3.5 \pm 2.8$ & 0.34 & $4.5 \pm 3.0$ & $3.9 \pm 2.8$ & 0.23 \\
\hline
\end{tabular}

Abbreviations: P4P pay for performance; STD standardized difference; SD standard deviation; NTD new Taiwan dollar; COPD chronic obstructive pulmonary disease; $P A O D$ peripheral artery occlusive disease; VTE venous thromboembolism; DM diabetes mellitus; NSAID non-steroidal anti-inflammatory drug; COX-II cyclooxygenase II; DDP4 Dipeptidyl peptidase 4 inhibitors

Data were presented as frequency (percentage) or mean \pm standard deviation

date of withdrawal from the NHI program or December 31, 2013, whichever came first.

\section{Statistical analysis}

To reduce possible confounding of variables due to treatment selection-bias, PSM method was used in this study. The propensity score was the predicted probability of being included the P4P group given the values of covariates using the multivariable logistic regression without interaction effects. The variables selected to calculate the propensity score are listed in Table 1 where the follow up year was replaced with the index date.
Each patient in the P4P group was matched with one counterpart in the non-P4P group. The matching was conducted using a greedy (nearest neighbor) algorithm with a caliper of 0.2 times of the standard deviation of the logit of propensity score, with random matching order and without replacement. The quality of matching was checked using the absolute value of standardized difference (STD) between the groups, where a value less than 0.1 was considered negligible difference.

The risks of time to fatal event outcomes (i.e., infection-related death and all-cause mortality) between the groups were compared using the Cox proportional 
hazard model. The time to non-fatal event outcomes (i.e., infection events) between groups were compared using the Fine and Gray subdistribution hazard model which considered all-cause mortality a competing risk. The difference in the number of events between the groups was compared using Poisson model in which the natural logarithm of follow up duration was treated as the offset variable. The study group was the only explanatory variable in the survival and Poisson models. The within-pair clustering of outcomes after PSM was accounted for by a robust standard error, which is known as the marginal model [26].

Subgroup analysis for any ER infection event and infection-related death were conducted on 6 prespecified subgroup variables, including sex, age (20-39 years, 40-64 years and $\geq 65$ years), diabetes duration (dichotomized by 5 years), CKD, CCI score (dichotomized by 2 scores) and infection-related hospitalization in the previous 3 years. A two-tailed $P$ value $<0.05$ was considered to be statistically significant and no adjustment for multiple testing (multiplicity) was made in this study. All statistical analyses were performed using SAS version 9.4 (SAS Institute, Cary, NC), including the "psmatch" procedure for PSM and the macro "\%cif" for generating cumulative incidence function under the Fine and Gray subdistribution hazard method.

\section{Results}

\section{Baseline patient characteristics}

Table 1 lists the baseline characteristics of the patients included and not included in the P4P program before and after matching. Before matching, the P4P group was younger, had fewer ER visits and hospitalizations, lower prevalence of chronic obstructive pulmonary disease, dialysis, heart failure, stroke, and malignancy, but had longer diabetes duration, more outpatient health care utilization, higher prevalence of dyslipidemia and CKD. The two cohorts were similar in terms of the CCI score.
After matching, there was no substantial difference (STD absolute value $<0.1$ ) between the two groups. The mean follow-up duration was longer in the P4P group (4.5 years vs. 3.9 years).

\section{Outcomes}

The results showed that completing the first year P4P program was associated with a decreased risk of any ER infection event $(27.2 \%$ vs. $29 \%$; subdistribution hazard ratio [HR] 0.87, 95\% confidence interval [CI] 0.86-0.88) (Fig. 2a). The number needed to treat (NNT) was 58. According to the present results completing the first year P4P program may reduce the risks of all sites of ER infection events, except respiratory infection, with NNTs ranging between 36 and 5916. The risk of infectionrelated death was significantly lower in the P4P group than in the non-P4P group (4.1\% vs. $7.6 \%$; HR $0.46,95 \%$ CI $0.45-0.47$ ) with an NNT of 28 (Fig. 2b). In addition, completing the first year P4P program was associated with fewer events of all-cause ER visits, infection-related ER visits, all-cause hospitalization, and infection-related hospitalization during the follow up period. The risk of all-cause mortality was also significantly lower in the P4P group than in the non-P4P group (11.3\% vs. $21.2 \%$; HR $0.45,95 \%$ CI 0.45-0.46, NNT = 10) (Table 2).

\section{Subgroup analysis}

We performed two subgroup analyses on the occurrence of all-cause ER infection events and infection-related deaths. The results suggested that the effect of P4P on ER infection events and infection-related deaths was more apparent in the subgroups of patients who were female, had diabetes duration $\geq 5$ years, CKD, higher $\mathrm{CCI}$ scores and infection-related hospitalization in the previous 3 years. For patients aged $\geq 40$ years old, risk reduction was more obvious for any ER infection events, but not for infection-related deaths (Figs. 3a-b).
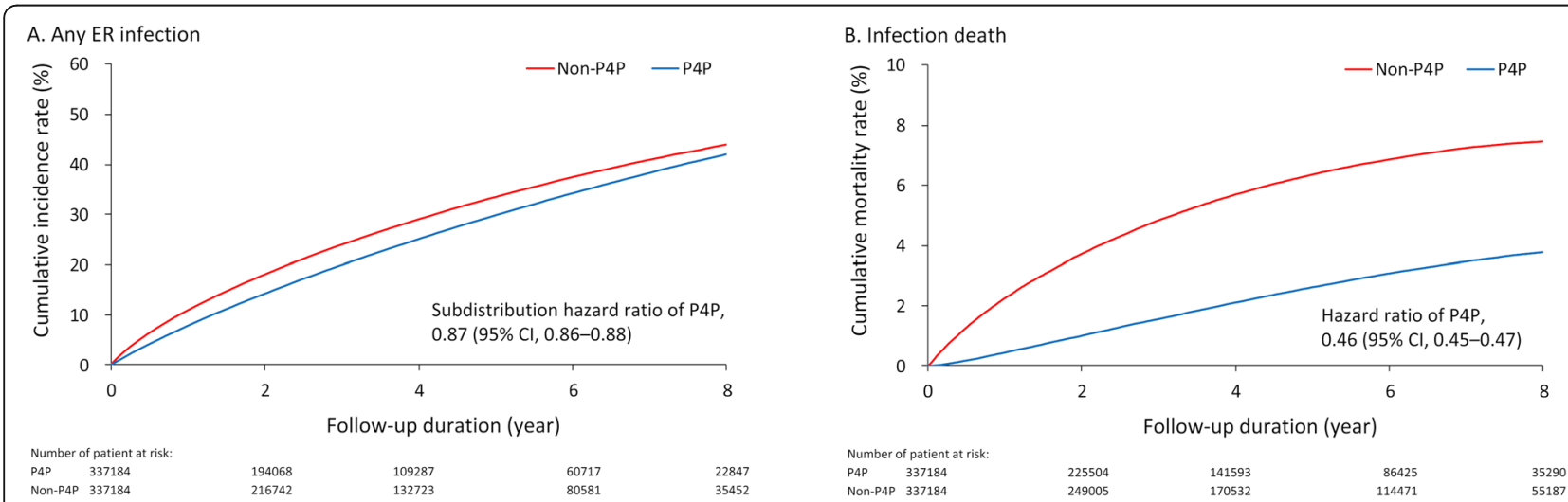

Fig. 2 Cumulative incidence function under Fine and Gray method of any ER infection event (A) and cumulative event rates of infection death (B) of patients with or without one-year P4P program in the propensity score matched cohort 
Table 2 Follow up outcomes in patients according to completing 1-year pay-for-performance program or not

\begin{tabular}{|c|c|c|c|c|}
\hline Outcome & $\mathrm{P} 4 \mathrm{P}(n=337,184)$ & Non- P4P $(n=337,184)$ & RR, HR or SHR of P4P $(95 \% \mathrm{CI})$ & NNT \\
\hline \multicolumn{5}{|l|}{ ER visit due to infection } \\
\hline Bacteremia & $29,694(8.8)$ & $39,084(11.6)$ & $0.46(0.45-0.47)$ & 36 \\
\hline Cardiovascular & $276(0.08)$ & $427(0.13)$ & $0.62(0.53-0.72)$ & 2233 \\
\hline Central nervous & $656(0.19)$ & $713(0.21)$ & $0.88(0.79-0.98)$ & 5916 \\
\hline Respiratory & $15,706(4.7)$ & $14,725(4.4)$ & $1.02(0.997-1.04)^{*}$ & 344 \\
\hline Gastrointestinal & $46,007(13.6)$ & $49,870(14.8)$ & $0.87(0.86-0.88)$ & 87 \\
\hline Genitourinary & $54,131(16.1)$ & $57,449(17.0)$ & $0.89(0.88-0.90)$ & 102 \\
\hline Musculoskeletal & $2581(0.77)$ & $2852(0.85)$ & $0.86(0.82-0.91)$ & 1244 \\
\hline Device-related infection & $3432(1.02)$ & $3810(1.13)$ & $0.86(0.82-0.90)$ & 892 \\
\hline Any infection event & $91,856(27.2)$ & $97,720(29.0)$ & $0.87(0.86-0.88)$ & 58 \\
\hline Infection death & $13,882(4.1)$ & $25,752(7.6)$ & $0.46(0.45-0.47)$ & 28 \\
\hline \multicolumn{5}{|l|}{ Annual number of events during the follow up } \\
\hline Number of all-cause ER visit & $2.24 \pm 4.88$ & $2.04 \pm 4.56$ & $0.94(0.93-0.95)$ & NA \\
\hline Number of infection-related ER visit & $0.40 \pm 1.14$ & $0.37 \pm 1.07$ & $0.91(0.90-0.92)$ & NA \\
\hline Number of all-cause hospitalization & $1.49 \pm 3.05$ & $1.50 \pm 2.92$ & $0.85(0.84-0.86)$ & NA \\
\hline Number of infection-related hospitalization & $0.48 \pm 1.38$ & $0.54 \pm 1.40$ & $0.76(0.75-0.77)$ & NA \\
\hline All-cause mortality & $38,234(11.3)$ & 71,587 (21.2) & $0.45(0.45-0.46)$ & 10 \\
\hline
\end{tabular}

Abbreviations: $P 4 P$ pay for performance; $C l$ confidence interval; $R R$ rate ratio; $H R$ hazard ratio; SHR subdistribution hazard ratio; $C l$ confidence interval; $E R$ emergency room; ICU intensive care unit; NNT number needed to treat; NA not applicable; Data were presented as frequency (percentage) or mean \pm standard deviation;

* Not statistically significant

\section{Discussion}

This large population-based cohort analysis showed that the P4P program may significantly reduce (by $13 \%$ ) the risks of ER infection events and infection-related hospitalization during the long-term follow up. Those benefits associated with a decreased risk of infection could improve the survival rate of the diabetic population and reduce the cost of medical health care through good care quality of P4P program [27].

Iain M. Carey et al. documented that T2DM patients who were aged $>70$ years, obese, smoking, had longer diabetes duration, and living in more deprived areas had a higher risk of infection [7]. This is consistent with our study, which showed patients who had diabetes for more than 5 years, more than $40 \%$ of moderate urban level, higher ratio of CKD, and slightly higher proportion of insulin use. Those risk factors contribute to more diabetes-related complications, and how to optimize the comprehensive care was an essential issue. Under highquality P4P program, serial diabetes-related tests and sustained improvement in continuity of care were both associated with lower risk of hospitalizations [4, 28], as well as early detection of unfavorable events including infections.

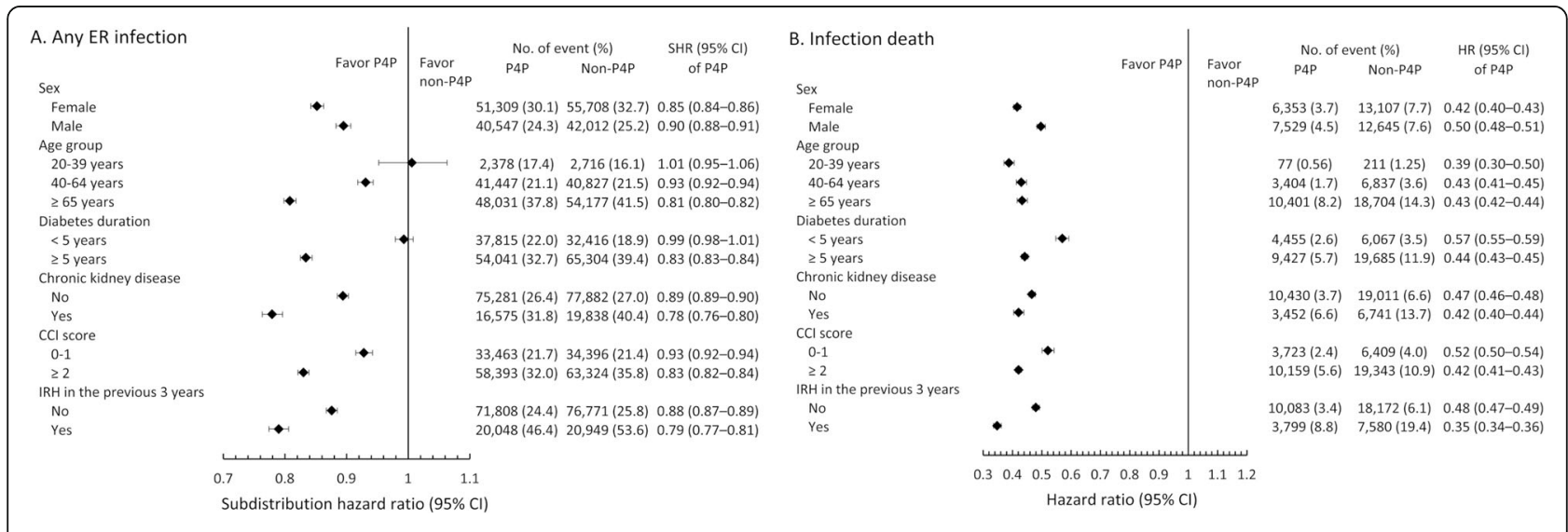

Fig. 3 Pre-specified subgroup analysis of any ER infection event (A) and infection death (B) 
Urinary tract infection is the most common infection that accounted for $30 \%$ of ER visits in diabetic patients, followed by GI infection and bacteremia [6, 29]. Esper and his colleagues also documented that diabetic patients had a higher prevalence of GU infections (DM vs. non-DM $28 \%$ vs. $22 \%$ ), and respiratory infections complicated with acute respiratory failure were significantly less frequent in the DM population [30]. In addition, they also found that diabetic patients with GU infections tended to suffer from acute renal failure, which might be a potential risk of mortality. Overall, those patients receiving P4P may get more survival benefit (reducing risk of infection-related death by $54 \%$ and all-cause mortality by $55 \%$ ) through great risk reduction effect on the most common ER infections, including GU infection (16.1\%, $\mathrm{NNT}=102)$, followed by GI infection $(13.6 \%, \mathrm{NNT}=87)$ and bacteremia $(8.8 \%, \mathrm{NNT}=36)$.

All-cause mortality was noted to be almost twice as high for adults with T2DM than for the healthy adult population [31]. Major mortality causes other than infections included diseases of the circulatory system, respiratory system, endocrine, nutritional, and metabolic diseases [5]. Less literature discussed infection death among T2DM patients [18, 32]. In our study, the risk of infection-related death and all-cause mortality were both significantly lower in the P4P group than in the non-P4P group, which is consistent with previous investigations $[16,18,32]$. The P4P program was suggested to result in more frequent measures of $\mathrm{HbA} 1 \mathrm{C}$ and set appropriate target of glycemic control [33]. High quality of diabetes care and adequate glycemic control could reduce macroand micro-vascular complications, which both have been reported to affect outcomes of hospitalization [28, 29]. Poor glycemic control was not only related to higher risk of infection [27], but also higher mortality. HbA1c level $>=6.5 \%$ was found to be a significant, independent predictor of severe organ dysfunction progression and mortality in sepsis [34]. Moreover, hypoglycemia with glucose level of less than $100 \mathrm{mg} / \mathrm{dL}$ was also associated with higher mortality $[35,36]$. In our study, the cohort in P4P had a slightly higher percentage of insulin therapy, which was a risk factor for hypoglycemia and associated mortality. Although there is limited evidence on whether participation in the diabetes $\mathrm{P} 4 \mathrm{P}$ program results in a better HbA1c level or not $[33,37]$, increased medication compliance and diet education in P4P may contribute to better glycemic stabilization and less risk of hypoglycemia, which could help to survive sepsis.

We noted the effect of P4P on ER infections and infection-related death was more apparent in female patients with diabetes duration $\geq 5$ years, CKD, and higher CCI scores. A higher risk of infection-related hospitalization was noted in patients with longer DM duration and increased with patient's age and components of multiple comorbidities in the research conducted by Iain M. Carey et al. [7]. Prolonged diabetes also contributed to leukocyte dysfunction, impaired immunity, anatomical abnormalities of the urinary tract and urinary dysmotility [38, 39]. Female diabetic patients had a higher incidence of GU infections in our study. Although sicker patients were usually excluded from the P4P program [22], those elder patients with longer DM duration, multiple comorbidities, and higher disease severity would potentially get more serious infectionrelated complications including shock and coma. For patients with more frequent infection-related hospitalization in the previous 3 years, P4P also showed a more risk reduction on recurrent ER infection events and potential infection-related deaths. Reduction of recurrent infections may result in a decrease in drug resistance bacteremia, improvement in the immune response, serious complications, and cost of hospitalization. The P4P program increased physician visits, serial exams and could raise medical expenses. However, the benefits outweigh costs due to expected reduction of ER visits and avoidance of infection-related complications during hospitalization.

Our study had several strengths including being a population-based study with a large sample size and long-term observation. However, we still had some inherent limitations caused by the retrospective analysis. First, Taiwan's NHI Program is a single player system, which is different from health care systems in some other countries. The different program design could limit the application of the $\mathrm{P} 4 \mathrm{P}$ program and demonstrate different effects in other regions. Second, the NHIRD limitations include the lack of records on selfpaid healthcare and disease severity. We balanced the disease severity among both cohorts by collecting details of multiple comorbidities, medication intake and the CCI score. Third, the laboratory information including HbA1c and the glycemic level were not analyzed in this study. The effects of chronic glycemic control and glycemic control target on T2DM-associated infection need further studies. Fourth, the culture reports and antibiotic sensitivity were unviable in the analysis. However, the data might affect the duration of hospitalization and complications but was not associated with ER infectionrelated visit.

\section{Conclusions}

In summary, our study showed that the diabetes P4P program may significantly decrease the risk of infection events, infection-related hospitalization, and mortality. The beneficial effects emerged to be more prominent in patients with longer diabetes duration, multiple comorbidities, and frequent previous infection-related hospitalization, indicating that enhancing 
multidisciplinary diabetes care on those sicker patients is clearly needed. However, we need further large, randomized control studies to confirm those findings.

\section{Supplementary Information}

The online version contains supplementary material available at https://doi. org/10.1186/s12913-021-06091-2.

Additional file 1 Supplemental Table 1. ICD-9 CM diagnostic codes. Diagnosis is registered according to the International Classification of Diseases, Ninth Revision, Clinical Modification (ICD-9-CM) codes.

\section{Abbreviations}

P4P: Pay for Performance; ER: emergency room; HR: Hazard ratio; Cl: Confidence interval; DM: Diabetes mellitus; CKD: Chronic kidney disease; T1DM: Type 1 diabetes mellitus; T2DM: Type 2 diabetes mellitus; NHIR D: National Health Insurance Research Database; NHI: National Health Institute; BNHI: Bureau of National Health Insurance; ICD-9-CM: International Classification of Diseases, Ninth Revision, Clinical Modification: HbA1c: Glycated hemoglobin; ALT: Alanine aminotransferase; LDL: Total cholesterol, low-density lipoprotein; TG: Triglyceride; HDL: High-density lipoprotein; CCl: Charlson's Comorbidity Index; Gl: Gastrointestinal; GU: Genitourinary; STD: Standardized difference; PSM: Propensity score matching; NNT: Number needed to treat; NTD: New Taiwan dollar; COPD: Chronic obstructive pulmonary disease; PAOD: Peripheral artery occlusive disease; VTE: Venous thromboembolism; NSIAD: Non-steroidal antiinflammatory drug; COX-II: Cyclooxygenase II; DDP4: Dipeptidyl peptidase 4; ICU: Intensive care unit

\section{Acknowledgements}

The authors thank Alfred Hsing-Fen Lin and Ben Yu-Lin Chou for assistance with statistics.

\section{Authors' contributions}

All authors contributed to statistical analysis and writing of the study. YFW and MYC participated in study design, acquisition of the data, critical review and wrote the manuscript; THC participated in acquisition of data and designed the research; PCW and YSP participated in the analysis and interpretation of data; MSL collected data and contributed to study direction. All authors have read and approved the manuscript.

\section{Funding}

The study was supported by a grant from Chang Gung Memorial Hospital (BMRP148 and FCRPF6K0011). This work was also supported by grants from the Chang Gung Memorial Hospital, Taiwan (CGRPG2F0011, CLRPG2C0021, CLRPG2C0022, CLRPG2C0023, CLRPG2C0024, CLRPG2G0081, and CLRP G2G0082)

\section{Availability of data and materials}

The data used to support the findings of this study are available from the corresponding author upon request.

\section{Ethics approval and consent to participate}

This study was approved by the Institutional Review Board of the Chang Gung Memorial Hospital (IRB No.:202000134B1). The databases of NHIRD is only open to academic personnel in Taiwan for research purposes. We got administrative permission from the Health and Welfare Data Science Center to access and use the study data in Taiwan. No informed consent is required because the NHIRD contains de-identified public data released for research.

\section{Consent for publication}

Not applicable.

\section{Competing interests}

The authors declare that they have no competing interests.

\section{Author details}

'Department of Emergency Medicine, Chang Gung Memorial Hospital,

Chiayi, Taiwan. ${ }^{2}$ Department of Nursing, Chang Gung University of Science and Technology, Chiayi, Taiwan. ${ }^{3}$ Department of Nursing, Chang Gung University, Taoyuan, Taiwan. ${ }^{4}$ Department of Cardiology, Chang Gung Memorial Hospital, Keelung, Taiwan. ${ }^{5}$ Biostatistical Consultation Center of Chang Gung Memorial Hospital, Keelung, Taiwan Community Medicine Research Center of Chang Gung Memorial Hospital, Keelung, Taiwan. ${ }^{6}$ Chang Gung University, Taoyuan, Taiwan. ${ }^{7}$ Department of Cardiology, Chang Gung Memorial Hospital, Chiayi, Taiwan. ${ }^{8}$ Department of Endocrinology and Metabolism, Department of internal medicine, Chang Gung Memorial Hospital, Chiayi, Taiwan. ${ }^{9}$ Graduate Institute of Clinical Medical Sciences, College of Medicine, Chang Gung University, Taoyuan, Taiwan.

Received: 7 June 2020 Accepted: 14 January 2021

Published online: 21 January 2021

\section{References}

1. International Diabetes Federation. IDF diabetes atlas. Brussels: International Diabetes Federation; 2019. Available at: https://www.idf.org/aboutdiabetes/ what-is-diabetes/facts-figures.html. Accessed 21 March 2020

2. Kim EJ, Ha KH, Kim DJ, Choi YH. Diabetes and the risk of infection: a National Cohort Study. Diabetes Metab J. 2019:43(6):804-14.

3. Zhang P, Zhang X, Brown J, et al. Global healthcare expenditure on diabetes for 2010 and 2030. Diabetes Res Clin Pract. 2010:87:293-301.

4. Cheng J-SP, Tsai W-CD, Lin C-LMDMHS, et al. Trend and factors associated with healthcare use and costs in type 2 diabetes mellitus: a decade experience of a universal health insurance program. Med Care. 2015;53(2): $116-24$.

5. Bujang MA, Kuan PX, Tiong XT, et al. The all-cause mortality and a screening tool to determine high-risk patients among prevalent type 2 diabetes mellitus patients. J Diabetes Res. 2018;2018:4638327.

6. Korbel L, Spencer JD. Diabetes mellitus and infection: an evaluation of hospital utilization and management costs in the United States. J Diabetes Complicat. 2015;29(2):192-5.

7. Carey IM, Critchley JA, DeWilde S, Harris T, Hosking FJ, Cook DG. Risk of infection in type 1 and type 2 diabetes compared with the general population: a matched cohort study. Diabetes Care. 2018:41(3):513-21.

8. Casqueiro J, Casqueiro J, Alves C. Infections in patients with diabetes mellitus: A review of pathogenesis. Indian J Endocrinol Metab. 2012:16 Suppl 1(Suppl1):S27-36.

9. $\mathrm{Ma}$ CM, Yin FZ. The mortality in infectious inpatients with type 2 diabetes compared with non-diabetic population: infection in type 2 diabetes. Medicine (Baltimore). 2019;98(24):e16025.

10. Eijkenaar F. Pay for performance in health care: an international overview of initiatives. Med Care Res Rev. 2012;69(3):251-76.

11. Eijkenaar F, Emmert M, Scheppach M, Schöffski O. Effects of pay for performance in health care: a systematic review of systematic reviews. Health Policy. 2013;110(2-3):115-30.

12. Herck P, De Smedt $D$, Annemans L, Remmen R, Rosenthal MB, Sermeus W Systematic review: effects, design choices, and context of pay-forperformance in health care. BMC Health Serv Res. 2010;10:247.

13. Lee IT, Hsu CC, Sheu WH, Su SL, Wu YL, Lin SY. Pay-for-performance for shared care of diabetes in Taiwan. J Formos Med Assoc. 2019;118(Suppl 2): S122-9. https://doi.org/10.1016/j.jfma.2019.08.011 Epub 2019 Aug 27. PMID: 31471222

14. Yen SM, Kung PT, Sheen YJ, Chiu LT, Xu XC, Tsai WC. Factors related to continuing care and interruption of P4P program participation in patients with diabetes. Am J Manag Care. 2016;22(1):e18-30.

15. Cheng SH, Lee TT, Chen CC. A longitudinal examination of a pay-forperformance program for diabetes care: evidence from a natural experiment. Med Care. 2012;50(2):109-16.

16. Pan CC, Kung PT, Chiu LT, Liao YP, Tsai WC. Patients with diabetes in payfor-performance programs have better physician continuity of care and survival. Am J Manag Care. 2017;23(2):e57-66.

17. Coleman $\mathrm{K}$, Reiter KL, Fulwiler D. The impact of pay-for-performance on diabetes care in a large network of community health centers. J Health Care Poor Underserved. 2007:18(4):966-83.

18. Chen CH, Ma SH, Hu SY, et al. Diabetes shared care program (DSCP) and risk of infection mortality: a nationwide cohort study using administrative claims data in Taiwan. BMJ Open. 2018;8(7):e021382.

19. Tsai YS, Kung PT, Ku MC, Wang YH, Tsai WC. Effects of pay for performance on risk incidence of infection and of revision after total knee arthroplasty in 
type 2 diabetic patients: a nationwide matched cohort study. PLoS One. 2018;13(11):e0206797.

20. Lin LY, Warren-Gash C, Smeeth L, Chen PC. Data resource profile: the National Health Insurance Research Database (NHIRD). Epidemiol Health. 2018:40:e2018062.

21. Hsieh CY, Su CC, Shao SC, et al. Taiwan's National Health Insurance Research Database: past and future. Clin Epidemiol. 2019;11:349-58.

22. Chang RE, Lin SP, Aron DC. A pay-for-performance program in Taiwan improved care for some diabetes patients, but doctors may have excluded sicker ones. Health Aff (Millwood). 2012;31(1):93-102.

23. Zhou Z, Rahme E, Abrahamowicz M, Pilote L. Survival bias associated with time-to-treatment initiation in drug effectiveness evaluation: a comparison of methods. Am J Epidemiol. 2005;162(10):1016-23.

24. Dalrymple LS, Mu Y, Romano PS, et al. Outcomes of infection-related hospitalization in Medicare beneficiaries receiving in-center hemodialysis. Am J Kidney Dis. 2015;65(5):754-62.

25. Wu CY, Chen YJ, Ho HJ, et al. Association between nucleoside analogues and risk of hepatitis $B$ virus-related hepatocellular carcinoma recurrence following liver resection. Jama. 2012;308(18):1906-14.

26. Austin PC, Fine JP. Propensity-score matching with competing risks in survival analysis. Stat Med. 2019;38(5):751-77.

27. Chen $P C$, Lee $Y C$, Kuo RN. Differences in patient reports on the quality of care in a diabetes pay-for-performance program between 1 year enrolled and newly enrolled patients. Int I Qual Health Care. 2012;24(2):189-96.

28. Lin W, Huang IC, Wang SL, Yang MC, Yaung CL. Continuity of diabetes care is associated with avoidable hospitalizations: evidence from Taiwan's National Health Insurance scheme. Int J Qual Health Care. 2010;22(1):3-8.

29. Yo CH, Lee MT, Gi WT, et al. Prognostic determinants of communityacquired bloodstream infection in type 2 diabetic patients in ED. Am J Emerg Med. 2014;32(12):1450-4.

30. Esper AM, Moss M, Martin GS. The effect of diabetes mellitus on organ dysfunction with sepsis: an epidemiological study. Crit Care. 2009;13(1):R18.

31. Röckl S, Brinks R, Baumert J, et al. All-cause mortality in adults with and without type 2 diabetes: findings from the national health monitoring in Germany. BMJ Open Diabetes Res Care. 2017;5(1):e000451.

32. Chen YC, Lee CT, Lin BJ, Chang YY, Shi HY. Impact of pay-for-performance on mortality in diabetes patients in Taiwan: a population-based study. Medicine (Baltimore). 2016;95(27):e4197.

33. LeBlanc $\mathrm{E}$, Belanger $\mathrm{M}$, Thibault $\mathrm{V}$, et al. Influence of a pay-for-performance program on glycemic control in patients living with diabetes by family physicians in a Canadian Province. Can J Diabetes. 2017 Apr;41(2):190-6.

34. Lee YS, Min KH, Lee SY, et al. The value of glycated hemoglobin as predictor of organ dysfunction in patients with sepsis. PLoS One. 2019;14(5): e0216397.

35. Schuetz $\mathrm{P}$, Jones $\mathrm{AE}$, Howell MD, et al. Diabetes is not associated with increased mortality in emergency department patients with sepsis. Ann Emerg Med. 2011;58(5):438-44.

36. Chang $\mathrm{CH}$, Wang JL, Wu LC, Chuang LM, Lin HH. Diabetes, Glycemic Control, and Risk of Infection Morbidity and Mortality: A Cohort Study. Open Forum Infect Dis. 2019;6(10):ofz358.

37. Yuan SP, Huang CN, Liao HC, Lin YT, Wang YH. Glycemic control outcomes by gender in the pay-for-performance system: a retrospective database analysis in patients with type 2 diabetes mellitus. Int J Endocrinol. 2014; 2014:575124.

38. Chiu AF, Huang MH, Wang CC, Kuo HC. Higher glycosylated hemoglobin levels increase the risk of overactive bladder syndrome in patients with type 2 diabetes mellitus. Int J Urol. 2012;19(11):995-1001.

39. Hu R, Xia CQ, Butfiloski E, Clare-Salzler M. Effect of high glucose on cytokine production by human peripheral blood immune cells and type I interferon signaling in monocytes: implications for the role of hyperglycemia in the diabetes inflammatory process and host defense against infection. Clin Immunol. 2018;195:139-48.

\section{Publisher's Note}

Springer Nature remains neutral with regard to jurisdictional claims in published maps and institutional affiliations.

Ready to submit your research? Choose BMC and benefit from:

- fast, convenient online submission

- thorough peer review by experienced researchers in your field

- rapid publication on acceptance

- support for research data, including large and complex data types

- gold Open Access which fosters wider collaboration and increased citations

- maximum visibility for your research: over $100 \mathrm{M}$ website views per year

At BMC, research is always in progress.

Learn more biomedcentral.com/submissions 